\title{
Autoinmunidad tiroidea Nuevos conceptos en la fisiopatología
}

\author{
Arturo Orrego Monsalve
}

Médico Internista Endocrinólogo, Miembro Honorario de la Asociación Colombiana de Endocrinología, Diabetes y Metabolismo.

$\mathrm{L}$ a glándula tiroides juega un papel esencial en la homeostasis metabólica. La enfermedad de Graves y la tiroiditis de Hashimoto tienen una prevalencia de $2 \%$ y constituyen las entidades autoinmunes más frecuentes en humanos ${ }^{(1)}$. Estas entidades se originan por la pérdida de la tolerancia a los antígenos tiroideos en personas genéticamente susceptibles en asociación con factores ambientales ${ }^{(2)}$.

Se ha obtenido un importante progreso en el conocimiento de los genes responsables de las enfermedades tiroideas autoinmunes. Además, se ha profundizado en los últimos años en los factores y procesos comprometidos en la ruptura de la tolerancia a los antígenos propios.

Hasta el momento no existe evidencia de que la enfermedad de Graves espontánea se presente en especies diferentes a la humana, en cambio la tiroiditis autoinmune ocurre espontáneamente en ciertos mamíferos y aves. La comprensión de la tolerancia a los autoantígenos y su ruptura que conduce a la producción de la autoinmunidad tiroidea puede esclarecerse con el examen de las siguientes preguntas en ambas entidades, la espontánea y la inducida en animales experimentales $\left.{ }^{(3)} .1\right)$ ¿Cuáles autoantígenos son responsables de la autoinmunidad que se desarrolla en humanos y otros animales? 2) ¿Qué procesos deben utilizarse en la producción de autoinmunidad en mamíferos no humanos? 3) ¿Por qué se produce autoinmunidad tiroidea en algunos humanos tratados para otras enfermedades? 4) ¿Se puede bloquear la autoinmunidad inducida, experimentalmente ${ }^{(2,3)}$.

Para tratar de responder estas preguntas se deben tener presentes no sólo las bases inmunológicas de la tolerancia sino también las características particulares de los autoantígenos tiroideos ${ }^{(3)}$. Debe tenerse en cuenta que entre las enfermedades autoinmunes, las tiroideas son las únicas en las cuales ha sido posible identificar, sin lugar a dudas, los autoantígenos capaces de jugar un papel en su patogénesis. Notablemente, los receptores de la TSH, la peroxidasa tiroidea (TPO*) y la tiroglobulina (Tg) llevan dentro de sí características únicas e inusuales que juegan un papel crítico en la ruptura de la tolerancia inmune que conduce a la autoinmunidad tiroidea ${ }^{(3-9)}$.

\begin{tabular}{|c|c|c|c|c|}
\hline \multicolumn{5}{|c|}{$\begin{array}{l}\text { Figura 1. Características y concentración de los antígenos intratiroideos: Tiroglobulina, peroxidasa } \\
\text { y receptor de la TSH (TSHR). La expresión de Tg, TPO y TSHR está medida en tiroides de roedores }\end{array}$} \\
\hline & \multicolumn{3}{|c|}{ A. Autoantígenos tiroideos } & \multirow{2}{*}{$\begin{array}{c}\text { B. } \\
\text { Receptor de la TSH } \\
\text { (Holorrecentor) }\end{array}$} \\
\hline & $\begin{array}{l}\text { Tiroglobulina } \\
\text { (tg) }\end{array}$ & $\begin{array}{c}\text { Peroxidasa } \\
\text { tiroidea (TPO) }\end{array}$ & $\begin{array}{l}\text { Receptores de la TSH } \\
\text { (subunidad A) }\end{array}$ & \\
\hline Tipo de proteína & Soluble & Unión a membrana & Soluble & \\
\hline Tamaño KDa & $2 \times 300$ & $2 \times 100$ & Aprox. $60 \%$ & \\
\hline Concentración tiroidea & ++++ & ++ & + & \\
\hline Glucosilación & $12 \%$ & $10 \%$ & Aprox. $40 \%$ & \\
\hline Unión a receptor de manosa & Sí & No & Sí & \\
\hline Polimorfismo & Sí & No & Sí & \\
\hline Capacidad inmunogénica & Alta & Alguna & Alguna & \\
\hline
\end{tabular}

Modificado de Endocrine review. 2014;25:59-105. 


\section{Autoantígenos tiroideos}

Los tres mayores autoantígenos son: la tiroglobulina, los receptores de la $\mathrm{TSH}^{*}$ (TSHR*) y la peroxidasa tiroidea; todos estos autoantígenos son moléculas glucosiladas, complejas que sufren, durante la traducción, modificaciones necesarias para llevar a cabo su papel en la función tiroidea y por su habilidad para estimular el sistema inmune ${ }^{(3)}$ (figura 1).

\section{Tiroglobulina}

Es el antígeno tiroideo más abundante, cuya presencia posteriormente se demostró en el timo. Es una molécula soluble compuesta de dos monómeros de 330-kDa que sufre yodación. Esta etapa es crítica para el normal funcionamiento de la tiroglobulina como una prohormona portadora de T3 y T4. La presencia de yodo no es necesaria para que sea reconocida por los autoanticuerpos ${ }^{(3)}$.

\section{Peroxidasa tiroidea}

Esta enzima es la primera involucrada en la síntesis hormonal. Está compuesta por dos subunidades, cada una de $107-\mathrm{kDa}$, con un grupo prostético. La porción hemo es esencial para la actividad enzimática, pero no es indispensable en el reconocimiento por autoanticuerpos ${ }^{(10,11)}$.

\section{Receptores de la TSH (TSHR)}

Los receptores de la TSH son miembros de la rodopsina de la familia de la proteína G. La porción extracelular está compuesta por una región rica en leucina. Después de llegar a la superficie del tirocito el receptor sufre un clivaje intramolecular en dos o más sitios, con pérdida de un péptido C; esta modificación da origen a una subunidad A extracelular acoplada por medio de uniones bisulfuro a la subunidad B que comprende la región restante unida al dominio transmembrana. La acumulación de evidencia sobre los receptores de la TSH y sus anticuerpos ha demostrado que es la subunidad A, y no otra región, el autoantígeno en la enfermedad de Graves ${ }^{(3,5)}$.

No existe evidencia contundente de que el NIS* (cotransportador sodio-yoduro) se comporte como un autoantígeno tiroideo $^{(12,13,14)}$. Tampoco se ha demostrado que los anticuerpos contra el factor de crecimiento insulínico-1 (IGF-1*) desempeñen papel importante en la patogénesis de la oftalmopatía de $\operatorname{Graves}^{(15,16)}$.

\section{Propiedades de la Tg, la TPO y la subunidad A de los receptores de la TSH como factores inmunogénicos}

El número de péptidos disponibles para la unión a los complejos mayores de histocompatibilidad (MHC*) y la presentación a la células $\mathrm{T}$ depende en parte del tamaño y de la disponibilidad de las proteínas. Como es de esperar, se pueden obtener más péptidos de la proteína $\mathrm{Tg}$, presente en mayor abundancia, que de la TPO, la cual es intermedia en tamaño y cantidad. Muchísimos menos péptidos se originan en la subunidad A de los receptores de la TSH, que no solamente existen en menor proporción que la Tg y la TPO sino que también están presentes en cantidades menores en la glándula tiroides ${ }^{(7,11,17)}$.

La glucosilación es importante para la unión de los antígenos a la superficie de la manosa de los receptores (TSHR) y para la internalización resultante ${ }^{(18)}$, proceso que intensifica la eficiencia de la respuesta de las células $\mathrm{T}^{(19)}$. El polimorfismo de la Tg y de los TSHR, pero no de la TPO, potencializa la autoinmunidad tiroidea ${ }^{(8,9,20,21)}$. Combinando estas características, la Tg es más inmunogénica que la TPO o la subunidad A de la $\operatorname{TSHR}^{(2,3)}$.

\section{Inmunidad tiroidea en humanos}

Los anticuerpos estimulantes de la tiroides (TSAbs*) que activan los receptores de TSH son la causa directa de la enfermedad de Graves ${ }^{(5)}$. En un pequeño número de individuos, los anticuerpos bloqueadores de la TSH (TBAbs*) que son inhibidores de los receptores de la TSH pueden producir atrofia tiroidea e hipotiroidismo ${ }^{(22,23)}$. Los TSHR, como probablemente también algunas células $\mathrm{T}$ específicas de los receptores de la TSH y ciertas citocinas, juegan un papel en la oftalmopatía y en la dermopatía de Graves ${ }^{(24)}$.

En el lado opuesto del espectro, la autoinmunidad debida a la TPO y a la Tg cursan con infiltración linfocítica de la glándula tiroides y en ocasiones con hipotiroidismo ${ }^{(9,10)}$. Muchos adultos, especialmente las mujeres, presentan anticuerpos clase IgG contra la TPO y la Tg, pero raramente progresan a hipotiroidismo ${ }^{(24)}$. La autopsia ha demostrado la presencia de infiltración linfocítica tiroidea y de anticuerpos antitiroideos circulantes en ausencia de enfermedad clínica ${ }^{(25)}$. La detección de estos anticuerpos en suero refleja una enfermedad subclínica (tiroiditis) en una glándula con una gran reserva funcional, demostrada por ultrasonido en pacientes vivos ${ }^{(26)}$. Consecuentemente, el término tiroiditis de Hashimoto se refiere a individuos con anticuerpos antitiroideos, incluso en ausencia de enfermedad clínica ${ }^{(27)}$. Se debe reconocer que muchos pacientes con enfermedad de Graves pueden ser portadores de anticuerpos contra la TPO y a veces contra la $\mathrm{Tg}$, lo que sugiere una superposición en la ruptura de la tolerancia contra más de uno de los antígenos tiroideos ${ }^{(27)}$.

\section{La tolerancia inmune}

En el desarrollo de la tolerancia están comprometidos procesos complejos que incluyen mecanismos periféricos y centrales capaces de eliminar o suprimir la reactividad de las células T (28-32).

\section{Tolerancia central}

Las células T inmaduras llegan al timo donde sufren varios cambios negativos y positivos de selección, tras los cuales sa- 
len como células T CD4+ o CD8+ deprivadas de la capacidad de unirse a autopéptidos. Este proceso ocurre en la corteza del timo ${ }^{(28)}$. Los receptores de las células T están compuestos de dos cadenas $(\alpha y \beta)$ (figura 2 ).

La tolerancia central está basada en una selección negativa de células T autorreactivas en la médula del timo ${ }^{(29)}$.

\section{Células $\mathrm{T}$ regulatorias}

La depleción de las células T autorreacctivas por la tolerancia central no necesariamente elimina todas las células de este tipo. Otro mecanismo potente que produce tolerancia compromete las células T regulatorias (Treg). Estas células se forman en el timo, pueden ser "naturales" o inducidas. Tanto las naturales como las inducidas expresan típicamente CD4, CD25 y el factor de transcripción Foxp $3^{(30)}$. Las citocinas toman parte en la acción de las células Treg.

\section{Células B}

Las células B portadoras de receptores para autoantígenos se convierten en tolerantes por varios mecanismos como la deleción clonal, la anergía (inactivación funcional), la edición de receptores y probablemente por competición con factores de crecimiento $^{(31)}$.

\section{Células dendríticas tolerogénicas}

Estas células contribuyen a la inmunidad y podrían ser consideradas como factores en la autoinmunidad ${ }^{(32)}$.

\section{Regulador autoinmune (AIRE)}

La expresión de un número de autoantígenos dentro del timo está regulada por AIRE. En su ausencia se hace presente la autoinmunidad, como ocurre en la distrofia APECED* (poliendocrinolopatía con distrofia ectodérmica más candidiasis ${ }^{(33,34)}$.

\section{Conceptos más aceptados y menos cuestionados en la patogénesis de las enfermedades autoinmunes tiroideas}

La autoinmunidad tiroidea involucra la pérdida de la tolerancia a proteínas tiroideas en individuos genéticamente susceptibles, en asociación con factores ambientales y en presencia de autoantígenos con características particulares ${ }^{(3-34)}$. La tiroglobulina, la peroxidasa tiroidea y los receptores de la TSH tienen diferentes capacidades inmunogénicas en relación con su tamaño, el poder de la glucosilación, la concentración intratiroidea y si son solubles o están unidos a las membranas ${ }^{(2-9)}$.

La tiroiditis espontánea ocurre en varios mamíferos, pero la enfermedad de Graves se desarrolla únicamente en huma-

Figura 2. Tolerancia central y "educación" de las células T en el timo en presencia de AIRE (regulador autoinmune) y en su ausencia. Los ratones deficientes de AIRE presentan disminución en los niveles de algunas autoproteínas en las células epiteliales de la médula del timo, lo que produce la reactividad de las células $\mathrm{T}$ y la producción de anticuerpos. En el humano, la diferencia de AIRE produce la poliendocrinopatía autoinmune asociada a la distrofia ectodérmica y a candidiasis (APECED)
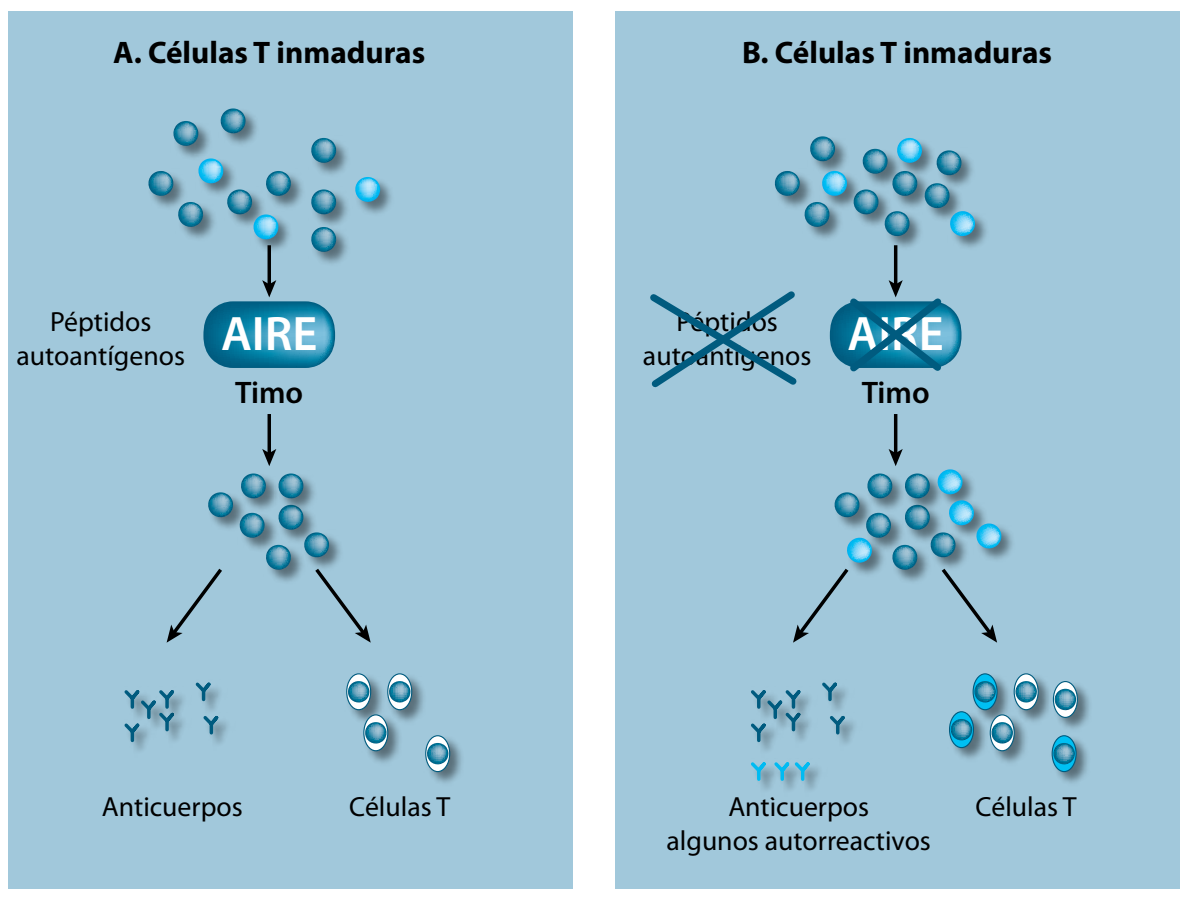

Modificado de Endocrine review. 2014;25:59-105. $\operatorname{nos}^{(3)}$. La tiroiditis puede producirse en roedores por métodos convencionales o por medio de procesos de inmunización recientes $^{(3)}$. Sin embargo, la enfermedad de Graves se produce únicamente con la inyección de células que expresan anticuerpos contra los receptores de la TSH o utilizando plásmidos o adenovirus como vectores ${ }^{(3,9)}$. En la tolerancia central la presentación de autoantígenos dentro del timo bloquea las células $\mathrm{T}$ inmaduras con alta afinidad por autoantígenos peptídicos. Las células $\mathrm{T}$ regulatorias producen mecanismos alternativos en la inhibición de las células $\mathrm{T}$ autoinmunes en la periferia. La tolerancia central producida por la expresión intratímica, es alta para la tiroglobulina y baja para la peroxidasa tiroidea y los receptores de TSH. Las células $\mathrm{T}$ regulatorias (Treg) no están comprometidas en la tolerancia a los receptores de la TSH, en cambio manejan el control del balance entre la enfermedad de Graves y la tiroiditis ${ }^{(2,3)}$. La ruptura 
de la tolerancia a los TSHR necesita la contribución del Complejo Mayor de Histocompatibilidad y del polimorfismo en los hu$\operatorname{manos}^{(7)}$. La pérdida de tolerancia a la tiroglobulina antes que la peroxidasa tiroidea indica que la Tg es más inmunogénica que la segunda y que domina el proceso autoinmune ${ }^{(3)}$. La tolerancia es inducida por la administración de autoantígenos tiroideos antes de que se establezca la autoinmunidad ${ }^{(3)}$. La administración de interferón alfa para hepatitis C potencializa la autoinmunidad tiroidea en pacientes con inmunidad intacta. La enfermedad de Graves que se produce con la depleción de células $\mathrm{T}$ se debe a la reconstitución de la inmunidad ${ }^{(3)}$. La mayoría de los factores ambientales, inclusive el exceso de yodo, potencializan, pero no inducen autoinmunidad tiroidea ${ }^{(3)}$. Probablemente ocurre lo mismo con los microorganismos. Son múltiples los mecanismos que explican la pérdida de la tolerancia a las proteínas tiroideas. $\mathrm{Si}$ se desea inducir tolerancia para prevenir enfermedades tiroideas autoinmunes se debe tener en cuenta la predicción del riesgo genético del individuo al mismo tiempo que se deben utilizar antígenos específicos en la terapia preventiva ${ }^{(35)}$.

\section{Conclusiones}

Es improbable que pueda invocarse un mecanismo único que explique la pérdida de tolerancia a las proteínas tiroideas como causa de la autoinmunidad contra esta glándula. Se tiene evidencia de que la tolerancia central (expresión intratímica de proteínas tiroideas), las células $\mathrm{T}$ reguladoras, los anticuerpos antitiroideos, tan particulares, asociados a susceptibilidad genética juegan factores esenciales. A pesar de su importancia, todos los factores ambientales potencializan, pero no inducen autoinmunidad tiroidea. Si se desea trabajar en la prevención de la autoinmunidad tiroidea debe tenerse seguridad en la predicción de los individuos en riesgo e identificar los antígenos específicos, con el fin de establecer futuros protocolos para inducir autotolerancia tiroidea. A este respecto, la ventaja con la autoinmunidad tiroidea es que los autoantígenos comprometidos en las enfermedades tiroideas autoinmunes son específicos y están claramente identificados.

\section{Referencias}

1. Hollowell JG Staehling NW,Flanders WD, et al. Serum TSH, T4, and thyroid antibodies in United States (1988 to 1994): National Health and Nutrition Examination Survey (NHANES III. J Clin Endocrinol Metab. 2002;87:489-499.

2. Tomer Y, Huber A. The etiology of autoinmune thyroid disease: a story of genes and environment. J autoinmmun. 2009;32:231-239.

3. McLachlan SM,Rapoport B. Breaking tolerance to thyroid antigens:Changing concepts in thyroid autoimmunity. Endocrine review.2014;25:59-105

4. McLachlan SM, Rapoport B. Thyroid peroxidase as an autoantigen. Thyroid 2007:17:939-948.

5. Rapoport B, McLachlan SM, Thethryrotropin receptor in Graves'disease. Thyroid. 2007; 17:938-948

6. Czarnocka B. Thyroperioxidase, Thyroglobulin, $\mathrm{Na}(+) / \mathrm{I}(-)$ symporter,pendrinin thyroid autoimmunity. Front Biosci (Land mark Ed). 2011; 16:783-802

7. Muixi, Carrascal M, Alvarez I, et al. Thyroglobulin peptides associate in vivo to HLA-DR in autoinmune thyroid gland. J Immunol. 2008;181:795-806.

8. Chazenbalk GD, Pichurin PN, GuoJ,et al. Interactions between the mannose receptor and thyroid autoantigens.Clin Exp Immunol.2005;139:216-224.

9. Brand OJ, Barret JC,Simmonds MJ, et al. Association of the thyroid stimulating hormone receptor gene (TSHR) with Graves disease. Human Mol Genet. 2009;18:1704-1713.

10. Grennan Jones F, Wolsten holme A, Fowler S, et al. High level expression of recombinant immunoreactive thyroid peroxidase in the high five insect cell line. J Mol Endocrinol. 1996;17:165-174.

11. Le Fourn V,Ferrand M, Franc JL. Endoproteolitic cleavage of human thyroperioxidase: role of the propeptide in the protein folding process . J Biol Chem. 2005;280:4568-4577

12. Dai G, Levy 0, Carrasco N.Cloning And characterization of the thyroid Iodide transporter. Nature. 1996;379:458-460.

13. Raspé E, Costagliola S, Ruf J, et al. Identification of the thyroid Na+/I- contrasporter as a potential autoantigen in thyroid autoinmune disease. Eur J Endocrinol. 1995;132:399-405.

14. Ajjan RA, Kemp EH, Waternan EA, et al. Detection of binding and blocking autoantibodies to the human sodium symporter in patients with autoimmune thyroid disease. J Clen Endocrinol Metab. 2000;85:2020-2027.

15. Smith TJ. JsIGF-1 receptor a tarjet for autoantibodies generation in Graves' disease?. J Clin Endocrinol Metab. 2013;98:515-518.

16. Varewijck AJ,Boelen A, Lamberts SW et al. Circulating IgGs may modúlate IGF1 receptor stimulating activity in a subset of patients with Graves' ophthalmopathy. J Clin Endocrinol Metab. 2013;98:769-776.

17. Misharin AV, Rapoport B, McLachlan SM. Thyroid antigen, no central tolarence, control reponses to immunization in BALB/c C57BL/6mice. Thyroid. 2009,19:503-509.
18. Stahl P, Gordon S. Expression of a mannosil.-fucosil receptor for endocytosis on cultured primary macrophages an their hybrids. J Cell Biol. 1982;93:49-56.

19. Engering AJ. Cella M, Fluitsma D, et al. The mannose receptor function as a high capacity and broad specifity antigen receptor in human dendritic cell. Eur J Immunol. 1997;27:2417-2425.

20. Tomer Y, Greenberg DA, Concepción E, et al.Thyroglulinis a thyroid specific gene for the familial autoinmune thyroid diseases. J Clin Endocrinol Metab. 2002;87:404-407.

21. McLachan SM. Interactions between the mannose receptor and thyroid autoantigens. Clin Exp Immunol. 2005;139: 216-224

22. Orgiazzi J, Williams DE, Chopra IJ, et al. Human thyroid adenyl ciclase stimulating activity in immunoglobulin G of patients with Graves' disease. J Clin Endocrinol Metab. 1976;42:341-354.

23. Endo K, Kasagi K, Konishi J, et al. Detection and properties of TSH binding inhibitors immunoglobulins in patients with Graves' disease and Hashimoto's Thyroiditis. J Clin Endicrinol Metab . 1978;46:734-739.

24. Khoo TK, Bahn RS. Pathogenesis of Graves'ophthalmopathy: the role of autoantibodies. Thyroid. 2007;17:1013-1018.

25. Prentice IM, Phillips DI, Sarsero D, et al. Greographical distribution of subclinical autoinmune thyroid disease in Britain: a study using highly sensitive direct assay for autoantibodies to thyroglobulin and thyroid peroxidase. Acta Endocrinol (Copenh). 1990;123:493-498.

26. Acar T,Ozbek SS, Erdogan M, Ozgen AG, et al. Us finding in euthyroid patients with positive antithyroid autoantibodies test compared to normal and hypothiroid cases. Diagn Interv Radiol. 2013;19:265-270.

27. Marcocci $\mathrm{C}$, Chiovato $\mathrm{L}$, Mariotti S, et al, Changes of circulating autoantibodies levels during and after the therapy with Graves' disease. J Endocrinol Invest. 1982;5:13-19

28. Yassai M, Ammon K, Goverman J, et al. A molecular marker for thymocitespositive selection of CD4 single-positive thymocites with shorter TCRB CDR3 during T cell development. J Inmmunol.2002;168:3801-3807.

29. Kappler JW, Roehm N, Marrack P. T cell tolerance by clonal elimination in the thymus. Cell . 1987;49:273-280.

30. Laurenco EV, La Cava A. Natural Regulatory T cell in autoimmunity. Autoimmunity.2011;44:33-42.

31. Thomas JW. Antigen-specific responses in autoimmunity and tolerance. Immunol Res.2001;23:235-244.

32. Guery L, Hugues S. Tolerogenic and activatory plasmocitoid dendritic cell in autoimmunity. Front Immunol. 2013;4:59-64.

33. Finnish German. APECED Consortium .An autoinmune disease, APECED, caused for mutations in a novel gene featuring two PHD-type zinc-finger domains. NalGenet. 1997;17:399-403.

34. Zhang M, Vacchio MS, Vistica BP, et al. T cell tolerance to neo-self antigen expressed cells: the soluble form is more effective tan the membrane-bound form. J Immunol. 2003; 170:3954-3962. 